\title{
FÁBULAS CIX Y CXXIII DE HIGINO: VARIANTES RESPECTO A LA TRADICIÓN CLÁSICA
}

Andrés Masiá González

1. Los datos que han llegado hasta nosotros acerca de la figura de Higino son muy confusos' ${ }^{1}$. La tradición habitual lo considera liberto de Augusto, igual que el fabulista Fedro, que titulaba su obra Phaedri Augusti liberti fabularum Aesopiarum libri y que, a su vez, era un esclavo de origen griego nacido en Macedonia ${ }^{2}$ o en Tracia, en lo que coincide con una de las tradiciones que hacen referencia al lugar de procedencia de Esopo.

Según cuenta Suetonio ${ }^{3}$, Higino era de ascendencia hispana y fue hecho prisionero en Alejandría por César y conducido a Roma. Augusto le concedio la libertad, de ahr que añadiera Gayo Julio a su nombre original. Se hizo cargo de la Biblioteca Palatina y era amigo de Ovidio y de Clodio Licinio, antiguo consul e historiador.

I Cf. una descripción más detallada sobre la biografía de este autor en el articulo de Tolkiehn, R.E. s. u. Iulius Hyginus.

2 Cf. Phaedr. III 19: Ego, quem Piero mater enixa est iugo.

${ }^{3}$ Suet. Gram. Rhet. 90, 20: C. IVLIVS HYGNVS Augusti libertus natione Hispanus - nonnuIli Alexandrinum putant a Caesare puerum Romam adductum Alexandria capta - studiose et audiit et imitatus est Comelium Alexandrum grammaticum Graecum. quem propter antiquitatis notitiam Polyhistorem multi, quidam Historiam vocabant. praefuit Palatinae bibliothecae, nec eo secius plurimos docuit: fuitque familiarissimus Ovidio poetae et Clodio Licinio consulari historico, qui ewn admodum pauperem decessisse tradit et liberalitate sua quoad vixerit sustentatum. huius libernus fuit lulius Modestus, in studiis atque doctrina vestigia patroni secutus. 
Había sido discípulo de uno de los principales estudiosos alejandrinos, Alejandro Polistor, y se convirtió en uno de los eruditos más grandes de su época. Sus escritos comprendían una amplia gama de temas: historia (Exempla, De familiis Troianis), geografía (De origine et situ urbium Italicarum), teología (De propietatibus deorum, de dis Penatibus), de agricultura (De apibus, De agri cultura).

Sin embargo, el Higino de las Fabulae con toda seguridad, como señala Rose en la introducción ${ }^{4}$ a su edición de esta obra, no fue un hombre culto, como lo era sin duda alguien que dirigía la Biblioteca Palatina y que, por tanto, gozaba de la consideración de Augusto y era amigo de Ovidio y de Clodio Licinio. El uso de un latín poco académico así lo demuestra, igual que su escaso dominio de la lengua griega, algo impensable para quien se supone que procedía de Alejandría.

Por otra parte, aunque no se puede asegurar, parece probable que el autor de las Fabulae fue el mismo que el de la Poetica astronomicas ${ }^{5}$, la otra obra atribuida a Higino que ha llegado hasta nosotros; existen semejanzas tanto formales como de contenido que así lo demuestran y, además, en algunos pasajes da la impresión de que el autor de la Astronomica remite a las Fabulae ${ }^{6}$. Por tanto, es posible que el autor de ambas obras fuese el mismo y algunos estudiosos han supuesto que los libros escritos correctamente por Gayo Julio Higino podrían haber sido reescritos posteriormente por un epitomador, que realiz6 una recopilación de sus textos en un latín no muy correcto, dándole la configuración de compendio mítico con que han llegado hasta nosotros. Sin embargo, esto obliga a considerar como cierto que el autor de la Astronomica fuera también Higino, lo que dista mucho de ser un hecho probado. Lo más apropiado es sin duda referirse al autor de estas obras como pseudo-Higino, al igual que se suele hacer con el repertorio mitográfico griego de pseudo-Apolodoro', una figura tan problemática como la del escritor romano.

Asimismo, dentro de la oscuridad que rodea la fecha en que se escribio esta obra, el único hecho demostrado es que era conocida en el 207 d.C. Es muy probable que en el s. II las fábulas fueran utilizadas como textos escolares.

4 Cf. H.I. Rose, Hygini Fabulae, Londres, 1933 (1963 r.), pp. III-VII.

s Sobre esta obra cf. las ediciones de A. le Bocuffle, L'Astronomie, Paris, 1983 y M. F. Vitobello, L'Astronomia, Bari, 1988.

- Cf. Astr. II 4 y su relación con Fab. CXXX, como señala Rose en pp. IV-V.

1 Cf. C. Robert, De Apollodori Bibliotheca, Berlin, 1873. G. Frazer, Apollodorus. The Libran;, Londres - Cambridge, 1921 (1990 r.), pp. IX-XX. R. Wagner, Apollodori Bibliotheca, Leipzig. 1926, p. V.

Cf. Rose, o.c. p. Vil. 
Como un dato que se puede aportar para intentar esclarecer la época de nuestro autor, hay que señalar que las CCLXXVII fábulas que la tradición nos ha legado y que son las que podemos encontrar tanto en la clásica edición de Rose como en la muy reciente de P.K. Marshall ${ }^{9}$, sólo dos citan en su título el nombre de un tragediógrafo cuya versión fue seguida sin duda por Higino a la hora de escribir sus compendios míticos. Estas fábulas son la IV Ino Euripidis y la VIII Eadem Euripidis quam scribit Ennius ${ }^{10}$, que se refiere a una Antiope del autor ático. Sin embargo, la alusión a Ennio está, con toda probabilidad, equivocada, pues no ha llegado hasta nosotros ninguna noticia de que el tragediógrafo rudino compusiera una obra con este título, aunque sí lo hizo su sobrino, Marco Pacuvio.

Por otra parte, existe la posibilidad de que el error en la atribución de la tragedia a Ennio no se debiera a un copista, como propuso Robert, sino que fuese cometido por el mismo compilador de este repertorio mitográfico. De esta forma podríamos reforzar la hipótesis más extendida sobre la época en que vivió nuestro mitógrafo: si el autor de las Fabulae cometió este error, es probable que fuese bastante posterior a la época de Augusto, pues Cicerón ${ }^{11}$, contemporáneo del Higino liberto de Augusto, atribuye Antiopa a Pacuvio, sin ninguna referencia a Ennio.

2. Dejando a un lado la controvertida figura del autor de este resumen de leyendas heróicas, podemos comprobar que la relación existente entre las $\mathrm{Fa}$ bulae y los mitos escenificados en el teatro griego resulta patente: de las doscientas setenta y siete fábulas atribuidas a Higino, descontando doce que se han perdido y cincuenta y nueve que corresponden a inventarios de personajes que coinciden en haber realizado un hecho determinado (p. ej.: Septem sapientes, Quae mortales cum Iove concubuerunt, Quae cum Apolline, Quae cum Neptuno... Qui patres suos occiderunt, Qui matres suas occiderunt, Qui fratres... Quae piae fuerunt, vel qui pii, Quae impiae fuerunt, Quae castissimae... Qui a Neptuno perierunt, vel a Mercurio, vel a Minerva) en ser descendientes de dioses (lovis filii, Neptuni filii, Vulcani filii...) o que recogen acontecimientos curiosos (Rerum inventores primi), nos quedan doscientas seis fábulas, de las cuales ciento siete comparten título con alguna tragedia griega de la que tenemos noticia y treinta y ocho de ellas corresponden a obras de Eurípides, aun-

- Hygini Fabulae, Stuttgart - Leipzig, B.T. 1993.

${ }^{10}$ C. Robert, «Die Phactonsage bei Hesiod», Hermes XVIII (1883) p. 436 n. 1, considera la alusión a Ennio como una interpolación de algún copista que se confundio tras haber realizado una lectura apresurada de Cic. Fin. I 4: quis enim tam inimicus paene nomini romano est, qui Ennii Medeam aut Antiopam Pacuvii spernat aut reiciat quod se isdem Euripidis fabulis delectari dicat? Cf. asimismo C. Desmedt, «Fabulae Hygini: VIII. Eadem Euripidis quam scribit Ennius», RBPh 50 (1972) pp. 70-77.

11 Cf. Cic. Fin. 1 2, 4; Div. I 13, 23; Acad. II 7, 20. 
que tal coincidencia no implique que el mitógrafo extractara en todos los casos las obras del tragediógrafo ateniense ${ }^{12}$.

Así pues, algo más de la mitad de las leyendas transcritas por Higino coinciden con títulos de tragedias representadas en el drama ático. El porcentaje es elevado, pero también nos sirve para constatar otro hecho: el resto de las fábulas trata sobre personajes cuya repercusión en la literatura ha sido mucho menor. Esto demuestra la importancia que el repertorio de Higino concede a mitos que podemos considerar secundarios, en contraste con el escaso tratamiento que la épica y la tragedia griegas han dado a estos personajes.

$Y$ aún podemos observar una peculiaridad más. Dentro de la conexión existente entre los resúmenes míticos de Higino y las tragedias a las que hacen referencia sus títulos, resumiendo los rasgos fundamentales del mito escenificado por el autor trágico correspondiente, se aprecia una serie de rasgos en los que el mitógrafo adoptaba una variante distinta a la de los textos épicos y trágicos conservados o, cuando menos, no los seguía exactamente.

3. Pasando al estudio de los personajes acerca de los que versa este trabajo, conviene señalar que Poliméstor y Neoptólemo, sin ser lo que podríamos llamar personajes secundarios propiamente dichos, sobre todo en el caso de Nepotólemo, son personajes que en la tradición literaria anterior que ha llegado hasta nosotros no gozaban de una relevancia especial.

Sin embargo, no hay que olvidar que Neoptólemo es uno de los protagonistas de Filoctetes de Sófocles; su actuación también es significativa en otras dos tragedias de Eurípides Hécuba y Andrómaca, aunque no aparece directamente en escena en ninguna de ellas. Asimismo, aunque en los poemas homericos sólo es mencionado en una ocasión por su padre Aquiles ${ }^{13}$, según la Crestomatía de Proclo, Neoptólemo era uno de los personajes relevantes en tres poemas del ciclo: Pequeña Ilíada ${ }^{14}$, Saco de Troya ${ }^{15}$ y Regresos ${ }^{16}$.

\section{Poliméstor}

4.1. Para estudiar el mito de Poliméstor, me he basado en la Fab. CIX, titulada Iliona, donde Higino aborda el mismo tema que Eurípides en la mayor parte de su Hécuba.

12 Cf. A. Martínez Diez, Fabulas de Higino y tragedias de Euripides, Granada, 1975.

${ }^{13}$ Cf. Il. XIX 327.

14 Cf. Procl. Chrest. p. 106 Allen.

15 Cf. ibid. p. 107-8 Allen.

${ }^{16}$ Cf. ibid. p. 108 Allen. 
Iliona era el nombre de la hija mayor de Príamo y Hécuba y estaba casada con Poliméstor, rey de Tracia. Según las versiones más extendidas, cuando comenzó la guerra de Troya, Príamo había enviado a uno de sus hijos más pequeños, Polidoro, a la corte de Poliméstor, para protegerlo del peligro. Además, le había confiado grandes tesoros para que los custodiara y para que el niño mantuviese su dignidad, en el caso de que la guerra no fuese favorable a los troyanos. Sin embargo, Poliméstor, fuera por codicia de los tesoros o por granjearse la simpatía de los griegos, asesinó a Polidoro. A continuación, arrojo su cadáver al mar y éste fue descubierto por una sirvienta de Hécuba o por la misma reina, cuando recogía agua para las honras fúnebres de Políxena, a la que los aqueos acababan de sacrificar sobre la tumba de Aquiles.

Veamos a continuación el texto ${ }^{17}$ correspondiente a esta fábula de Higino:

\section{ILIONA}

Priamo Polydorus filius ex Hecuba cum esset natus, Ilionae filiae suae dederunt eum educandum, quae Polymnestori regi Thracum erat nupta, quem illa pro filio suo educavit; Deipylum autem quem ex Polymnestore procreaverat, pro suo fratre educavit, ut si alteri eorum quid foret, parentibus praestaret. sed cum Achivi Troia capta prolem Priami exstirpare vellent, Astyanacta Hectoris et Andromachae filium de muro deiecerunt et ad Polymnestorem legatos miserunt, qui ei Agamemnonis filiam nomine Electram pollicerentur in coniugium et auri magnam copiam, si Polydorum Priami filium interfecisset. Polymnestor legatorum dicta non repudiavit, Deypylumque filium suum imprudens occidit, arbitrans se Polydorum filium Priami interfecisse. Polydorus autem ad oraculum Apollinis de parentibus suis sciscitatum est profectus, cui responsum est patriam incensam, patrem occisum, matrem in servitute te. neri. cum inde rediret et vidit aliter esse ac sibi responsum fuit <ratus> se Polymnestoris esse filium, ab sorore llionea inquisivit quid ita aliter sortes dixissent; cui soror quid veri esset patefecit, et eius consilio Polymnestorem luminibus privavit atque interfecit.

4.2. En principio, podemos observar que en esta fábula Andrómaca sólo es citada como madre de Astianacte. El personaje no atrae el interés del mitógrafo, aunque había sido tratado ampliamente por la tragedia griega y romana ${ }^{18}$.

17 Los textos de las fábulas que citamos son los editados por P. K. Marshall, o. c. pp. 98-9 y 107

18 Eurf́pides, Sófocles y Antifonte escribieron una Andrómaca. Asimismo, era uno de los per-

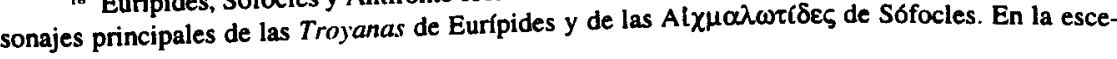


Analizando los restantes datos que nos ofrece este texto, Higino se aparta de la variante adoptada por Eurípides en su Hécuba, como veremos a continuación.

En la tragedia euripidea no se hace ninguna referencia a Iliona. El espec-

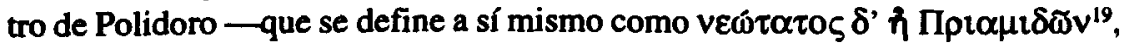
aunque en otros mitógrafos es Troilo el que consta como hijo menor de Príamo y $\mathrm{H}^{6} \mathrm{cuba}^{20}$ - hace referencia a su marcha a Tracia por motivos de seguridad; fue confiado a Poliméstor, que guardaba una estrecha relación de hospitalidad con Príamo, y llevó consigo una gran cantidad de riquezas ${ }^{21}$. Cuando los aqueos conquistaron Troya, Poliméstor, movido por la codicia, asesinó a su huésped (Eur. Hec. 21-7):

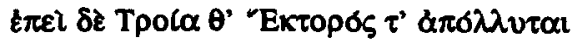

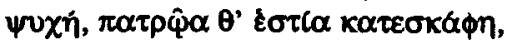

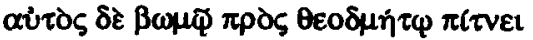

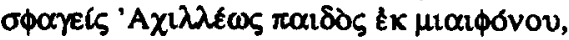

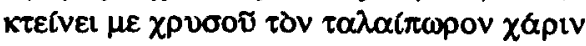

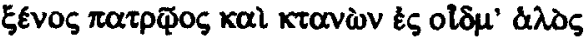

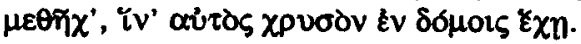

Estos versos ponen de manifiesto que en la tragedia de Eurípides Poliméstor asesinó al Priámida para apoderarse de los tesoros que éste había llevado consigo. En cambio, en el texto de Higino son los griegos quienes ofrecen una gran recompensa al rey tracio si acaba con la vida del príncipe troyano. Además, la proposición de los aqueos se ve acrecentada por un hecho inexistente por completo en la tragedia ática: la oferta de unir en matrimonio a Poliméstor con una hija de Agamenón.

Por lo general, las Fábulas de Higino se limitan a recoger una serie de hechos concretos. No son más que un repertorio mitológico que resume una serie de leyendas de sobra conocidas en la Antiguiedad a través de autores de diversos géneros literarios. Sin embargo, en algunas ocasiones, nos encontramos con que Higino, o quien quiera que fuese el autor de estas Fábulas, aporta una variante que otros mitógrafos no han recogido, como sucede en este caso con la propuesta matrimonial de Electra.

na romana, Ennio compuso una Andromacha aechmalotis y tenemos noticia de que Nevio tambien escribio una tragedia titulada Andromacha. Además, el personaje de la esposa de Hector cautiva debio de tener bastante notoriedad en Astyanax de Accio y en Hermiona de Livio Andronico, igual que sucede en las Troades de Séneca.

19 Eur. Hec. 13.

${ }^{20}$ Cf. Apd. Bibl. III 12, 5.

3 Cf. Hec. 6-12. 
En este mismo sentido, podemos resaltar la frase quem illa pro filio suo educavit; Deipylum autem... pro suo fratre educavit, ut si alteri eorum quid foret, parentibus praestaret. El hecho de que Iliona tuviese que responder. ante sus padres de la suerte de Polidoro es algo inherente a esta variante mítica y quizás pudo ser utilizado con anterioridad por Pacuvio en su Iliona. Han llegado hasta nosotros algunos fragmentos correspondientes a esta tragedia en los que podemos comprobar que el mito sigue la misma línea que en la fábula de Higino.

En el primer ejemplo, la sombra de Deípilo ruega a su madre que dé sepultura a sus restos (fr. 205-10 W):

Mater, te appello, tu quae curam somno suspenso levas

neque te me miseret, surge et sepeli natum... priusquam ferae volucresque... neu reliquias quaeso meas sieris denudatis ossibus per terram sanie delibutas foede divexarier.

El fragmento siguiente muestra a Iliona tramando, a instancias de Polidoro, la muerte de Poliméstor, para vengarse así del asesinato de Deípilo (fr. 218-9 W):

Di me etsi perdunt, tamen esse adiutam expetunt quom prius quam intereo spatium ulciscendi danunt

4.3. Asimismo, el educar a los niños como indica el texto de Higino, de forma que pudiesen adoptar la personalidad de uno o de otro indistintamente, es algo digno de reseñar.

Hay autores, como Kirk ${ }^{22}$, que sostienen que las parejas de gemelos en la mitología quieren destacar siempre un hecho ins6lito. Es bien sabido, por otra parte, que las parejas de gemelos más conocidas de la mitología (Cástor y Polideuces, Apolo y Ártemis, Rómulo y Remo, Casandra y Héleno) comparten alguna cualidad común, bien sea de función, como sucede en el caso de Apolo y Ártemis, dioses de la naturaleza y flechadores ambos ${ }^{23}$, o bien incluso de carácter, como en el caso de Rómulo y Remo.

22 Cf. El mito: su significado y funciones en las distintas culturas, Barcelona, 1973, p. 236.

${ }^{23}$ Cf. Ennio, Alcmeo fr. III Vahlen: Intendit crinitus Apollo / arcum auratum luna innixus / Diana facem iacit a laeva. 
Por contra, en la fábula de Higino, no se trata de dos gemelos sino de dos niños de padres distintos, educados para que pudieran intercambiar sus personalidades, quizás por motivos políticos.

Recuerda en cierta medida la alternancia de Cástor y Polideuces en el cielo; este suceso es transmitido por diversos autores ${ }^{24}$, como sucede en Odisea XI 298-304, donde Odiseo, en su descenso al Hades, cita a Leda como una de las mujeres que se le aproximaron:

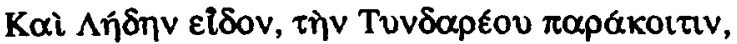

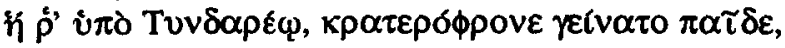

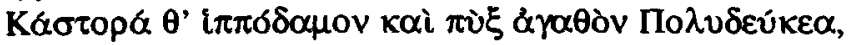

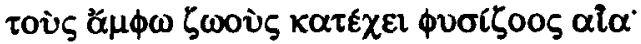

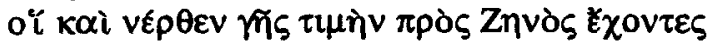

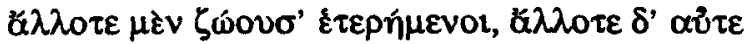

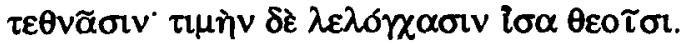

4.4. Por último, por lo que respecta a esta fábula, vamos a analizar la frase final de la misma, que hace referencia a la muerte de Poliméstor.

El texto de Higino pone de manifiesto sin lugar a dudas que Iliona acabó con la vida de su marido después de cegarlo, siguiendo los consejos de Polidoro's: et eius consilio Polymnestorem luminibus privavit atque interfecit.

En cambio, en la Hécuba de Eurípides no se produce la muerte del rey tracio, aunque se repite la cuestión de la ceguera y se añade, por si la escena no fuese ya bastante dramática, el asesinato de los hijos de Poliméstor, que en esta ocasión son dos.

En los vv. 1136-72, Poliméstor, tras haber sido cegado por las mujeres troyanas, relata lo sucedido a Agamenón e intenta, al mismo tiempo, justificar sus acciones ante el Atrida. De esta forma podemos oponer su punto de vista al de Hécuba, defendiendo sus actos un poco después en la misma tragedia ${ }^{26}$, y confrontarlo con el texto de Higino:

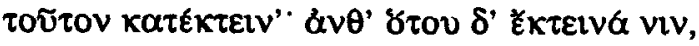

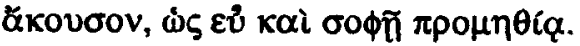

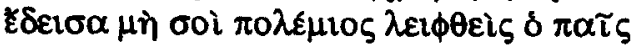

${ }^{24}$ Cf. Pi. N. X 55-91; P. XI 61-4. Luc. DDeor. XXVI. Apd. XI 2. Hyg. Fab. LXXX 4.

${ }^{25}$ El genitivo eius no aclara por completo quién planeó la muerte de Poliméstor y quién llevó a cabo el asesinato. Sin embargo, el propio Higino nos proporciona la respuesta a este dilema en la Fab. CCXL, QVAE CONIVGES SVOS OCCIDERVNT: Iliona Priami filia Polymenestorem regem Thracum.

${ }^{26}$ Cf. ibid. 1197-232. 


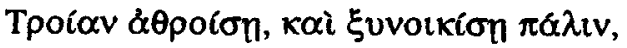

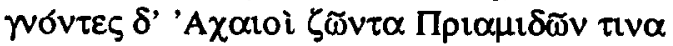

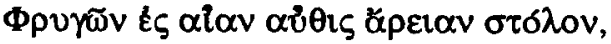

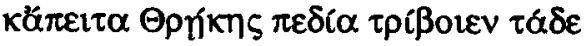

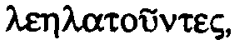

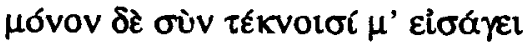

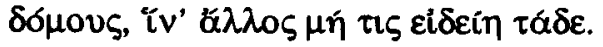

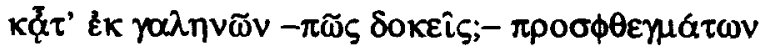

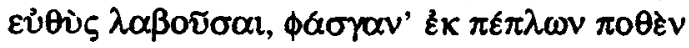

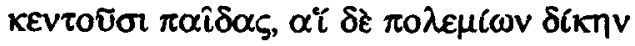

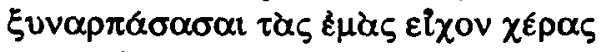

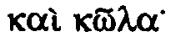

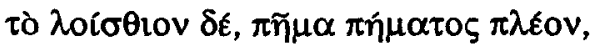

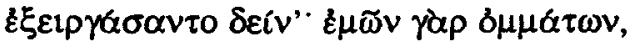

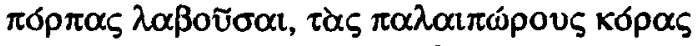

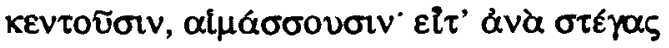

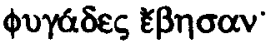

Todavía encontramos otra pequeña variante a la explicación de estos sucesos en el comentarista de Virgilio, Servio Danielino, Aen. III 15: fue la misma Hécuba con sus uñas la que cegó a Poliméstor:

cui Polydorum, filius ex Hecuba, Priamus pater initio belli Troiani... cum magno auri pondere educandum tradidit... amico et genero suo. sed illic deleta Troia... auri cupiditate adductus Polydorum... occidit... id cum matre Hecuba intellexisset, simulavit se ingens adhuc auri pondus velle secreto illi indicare... quod avarus rex... illius unguibus occaecatus est...

Por su parte, Ovidio en las Metamorfosis se refiere en dos ocasiones al crimen de Poliméstor, narrándolo de una forma muy similar a como lo hace Eurípides en su Hécuba (Ov. Met. XIII 429-38):

Est, ubi Troia fuit, Phrygiae contraria tellus

Bistoniis habitata viris: Polymestoris illic

regia dives erat, cui te commisit alendum

clam, Polydore, pater Phrygiisque removit ab armis, 
consilium sapiens, sceleris nisi praemia magnas

adiecisset opes, animi inritamen avari.

Vt cecidit fortuna Phrygum, capit inpius ensem

rex Thracum iuguloque sui demisit alumni

et, tamquam tolli cum corpore crimina possent,

exanimem scopulo subiectas misit in undas.

El mismo Ovidio, unos versos despues ${ }^{27}$, presenta la narración del atentado contra Poliméstor y los motivos que indujeron a Hécuba a cometerlo del mismo modo que en la versión de la Hécuba de Eurípides. No obstante, podemos observar una pequeña variante que la hace coincidir casi por completo con el comentario de Servio, al que nos hemos referido con anterioridad: no se menciona a los hijos de Poliméstor y, en los vv. 558-65, es la anciana madre de Polidoro la que, ayudada por las demás cautivas troyanas, arranca los ojos al rey tracio. Ovidio presenta un cuadro particularmente cruel de este suceso:

Spectat truculenta loquentem

falsaque iurantem tumidaque exaestuat ira atque ita correpto captivarum agmina matrum invocat et digitos in perfida lumina condit expellitque genis oculos (facit ira nocentem) inmergitque manus foedataque sanguine sontis non lumen, (neque enim superest) loca luminis haurit.

4.5. No podemos finalizar el comentario de esta fábula sin resaltar un hecho muy significativo acerca de las diversas variantes que se pueden encontrar en un punto concreto de un mito, como es, es en este caso, la muerte de Polidoro. En la Ilíada Polidoro nunca abandona Troya y, aunque era el menor de los hijos de Príamo, Aquiles lo mató en el campo de batalla ${ }^{28}$ (Il. XX 407-14):

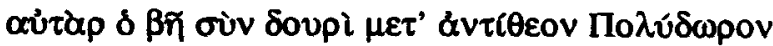

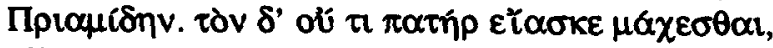

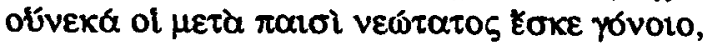

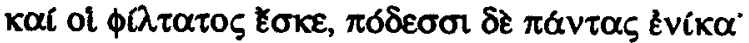

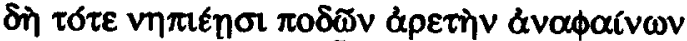

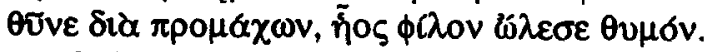

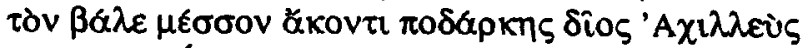

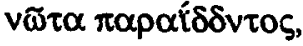

${ }^{27}$ Cf. ibid. $536-64$.

${ }^{28}$ Cf. Q. S. IV 155. 
4.6. Por tanto, de esta primera aproximación a Higino podemos destacar la presencia de algunas variantes respecto a la tradición anterior.

Lo más destacable es, sin duda, la posibilidad de que se pudiera producir el intercambio de los papeles de los niños, Deípilo y Polidoro, si la situación lo requiriese. Asimismo, Higino alude a una oferta de matrimonio que los griegos hicieron a Poliméstor, a fin de que se desposase con Electra. Ésta es una eventualidad no contemplada por el resto de las fuentes que transmiten esta leyenda.

Por otra parte, podemos observar que toda la tradición griega y latina referente al mito de Polidoro contrasta con los poemas homéricos, pues en la lliada el hijo de Príamo no abandona Troya y muere a manos de Aquiles.

\section{NEOPTOLEMO}

5.1. En cuanto al personaje de Neoptólemo, vamos a comenzar haciendo un breve resumen de su mito.

El hijo de Aquiles también era llamado Pirro, en alusión al nombre que recibía su padre cuando se ocultaba disfrazado de mujer en el gineceo del rey Licomedes, en Esciros ${ }^{29}$. Fue en esta época cuando Deidamía, hija del rey, quedó embarazada de Neoptólemo ${ }^{30}$, pero su nacimiento no se produjo hasta después que Aquiles hubiera partido hacia Troya. Tras la muerte del Pelida, los griegos capturaron al troyano Heleno, que posera dotes adivinatorias, igual que su hermana Casandra. Por él supieron que Troya no podría ser tomada sin la participación de Neoptólemo ${ }^{31}$ y sin el arco y las flechas de Heracles, que estaban en poder de Filoctetes ${ }^{32}$, confinado en Lemnos. Una embajada, de la que formaban parte Odiseo, FEnix y Diomedes, fue a buscar a Neoptólemo a Esciros y, al regresar a Troya, recogieron a Filoctetes. En Troya sus hazañas fueron numerosas, siendo uno de los héroes que se introdujeron en el caballo de madera ${ }^{33}$. Asesino a Príamo sobre el altar de Zeus Protector, despeño al hijo de Héctor, Astianacte, desde lo alto de la muralla y sacrificó a Políxena sobre la

29 Cf. Il. XIX 326-7. Ov. A. A. I 681-704. Apd. III 13, 8. Hyg. Fab. XCVI.

${ }^{30}$ Según otros autores, la madre de Neoptólemo fue Ifigenia. Cf. Duris en Jacoby, FGH 88 y Lyc. 183-91 y 323-4.

$"$ Cf. Apd. Ep. V 10. Prodi. Chr. p. 106 Allen.

${ }^{32}$ Cf. Soph. Ph. 604-9.

${ }^{33}$ Cf. Q. S. XII 275-315. 
tumba de Aquiles; en el reparto del botín, le correspondio la esposa de Héctor, Andrómaca ${ }^{34}$.

5.2. Hasta aquí, las fuentes coinciden al referirse a Neoptólemo. Es a partir de esta fase del mito cuando comienzan las divergencias entre las distintas variantes míticas en torno a lo que ocurrió con el destino del Eácida a su regreso de Troya. Para estudiar las diferentes versiones que al respecto han llegado hasta nosotros, vamos a pasar a continuación al análisis de la fábula CXXIII, titulada Neoptolemus:

\section{NEOPTOLEMVS}

Neoptolemus Achillis et Deidamiae filius ex Andromacha Eetionis filia captiva procreavit Amphialum ${ }^{35}$. sed postquam audivit Herminonem sponsam suam Oresti esse datam in coniugium, Lacedaemonem venit et a Menelao sponsam suam petit. cui ille fidem suam infirmare noluit, Hermionenque ab Oreste adduxit et Neoptolemo dedit. Orestes iniuria accepta Neoptolemum Delphis sacrificantem occidit et Hermionen recuperavit; cuius ossa per fines Ambraciae sparsa sunt, quae est in Epiri regionibus.

En primer lugar, por lo que respecta al personaje de Andrómaca, el texto del mitógrafo romano no aporta ninguna novedad. Apenas la cita y lo hace sólo para establecer la genealogía del único descendiente de Aquiles, Neoptólemo.

Sin embargo, ya hemos visto en el caso de la fábula anterior que Higino no se limita a realizar una exposición del mito sin más, sino que aporta alguna variante 0 , como sucede en este caso, podemos apreciar un elemento subjetivo en la exposición de los hechos: en la primera frase se comunica que Neoptólemo había tenido un hijo de Andrómaca. Después que hubiera ocurrido esto, un hecho que sin duda el mitógrafo consideraba importante, el hijo de Aquiles reclamó como suya a Hermíne, aunque antes de partir hacia Troya Menelao la había prometido a Orestes. En Andrómaca $964-70$, Orestes justifica su presencia en Ftía haciendo referencia al compromiso que lo unía con Hermíone, anterior a la boda de ésta con Neoptólemo:

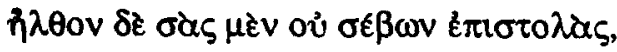

${ }^{34}$ Cf. Eur. Tr. 1126-35; Andr. argumentum I; 10-15; Hec. 523-80. Ov. Mer. XIII 453-81. Sen. Tro. 1148-57. Apd. Ep. V 21-4.

${ }^{35}$ Según Apd. Epit. VI 12, el hijo de Andrómaca y Neoptólemo se llamaba Moloso. Por su parte, Pausanias, I 11, 1 dice que los hijos fueron tres: Moloso, Píelo y Pérgamo. 


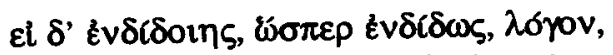
$\pi \varepsilon \mu \psi \omega \nu \sigma^{\prime} \alpha \pi^{\prime}$ o

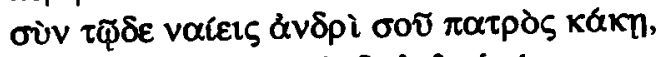

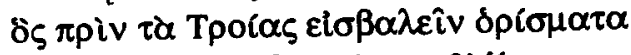

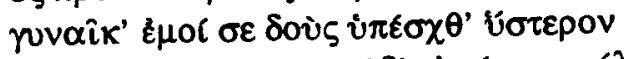

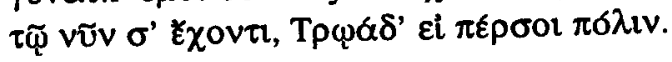

Ovidio transmite la misma versión que Eurípides. Hermíone fue su esposa antes que Menelao la prometiera a Neoptólemo. El siguiente fragmento pertenece a Heroidas VIII 15-22 y en él Hermíone incita a Orestes a que haga valer sus derechos como esposo, siguiendo el ejemplo de Menelao, que supo ir a rescatar a Helena:

At tu, cura mei si te pia tangit, Oreste,

Inice non timidas in tua iura manus.

An si quis rapiat stabulis armenta reclusis

Arma feras, rapta coniuge lentus eris?

Sit socer exemplo, nuptae repetitor ademptae,

Es posible que el autor de estas fábulas, con toda probabilidad de una época posterior a la de Ovidio, se basara en el texto del poeta. En el caso de que hubieran sido escritas por el Higino liberto de Augusto, ya hemos visto que mantuvieron una estrecha amistad, por lo que la influencia de Ovidio en la versión adoptada en la fábula no hubiera resultado extraña. Por tanto, quizás podamos plantearnos la posibilidad de que Higino esté justificando o, al menos, excusando el asesinato de Neoptólemo a manos de Orestes, pues éste se limitaba a defender su honor de una forma similar a como lo había hecho su tío Menelao antes que él.

La leyenda relativa a la enemistad entre Orestes y Neoptólemo tal como la representó Eurípides no difiere demasiado de lo que transmite el breve texto del mitógrafo romano. Únicamente existe un pequeño matiz que diferencia ambas versiones: en el texto latino encontramos las formas audivit y datam esse, lo que implica que la promesa hecha por Menelao a Neoptólemo era anterior al compromiso matrimonial contraído por el Atrida con su sobrino Orestes. Por el contrario, los vv. 966-70 de la tragedia euripidea no dejan lugar a duda acerca de la justificada recriminación de Orestes al deplorable comportamiento de Menelao, algo frecuente en la tragedia ática $^{36}$.

${ }_{36}$ Cf. Soph. Ai. 1040-162; Ph. 264-5; 314-16. Eur. IA 303-542; Andr. 319-32; 362-3; 425$62 ; 590-641$. 
En realidad, el Orestes euripideo únicamente está dando cumplimiento a su destino, que lo señalaba como el futuro marido de Hermíone. En el éxodo del Orestes 1653-7, Apolo aparece como deus ex machina y pone fin al enfrentamiento entre Orestes y Menelao, deteniendo al hijo de Agamenón cuando éste se dispone a clavar un puñal en el cuello de Hermíone, a la que mantiene como rehén:

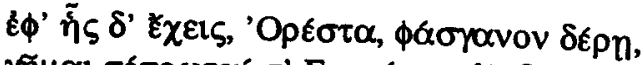

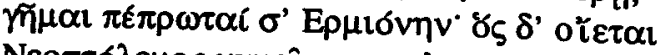

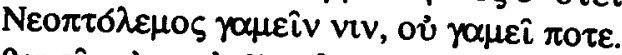

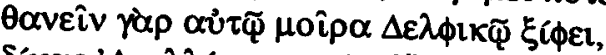

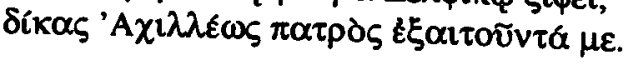

Un escolio al v. 1655 de esta tragedia euripidea nos muestra, junto a la versión del tragediógrafo ático, una variante muy sugestiva, por cuanto representa a Neoptólemo con unos rasgos humanitarios inusuales por completo en este personaje: según el escolio, el belicoso hijo de Aquiles se habría dirigido a Delfos en busca de una explicación a la falta de descendencia de su matrimonio (sch. Eur. Or. 1655):

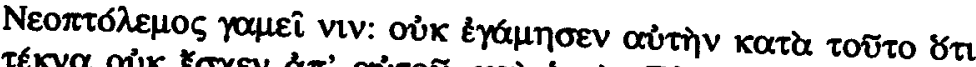

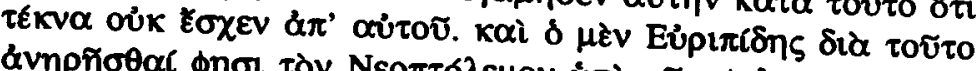

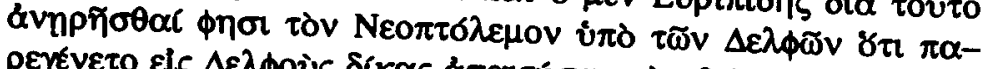

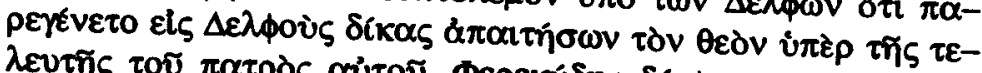

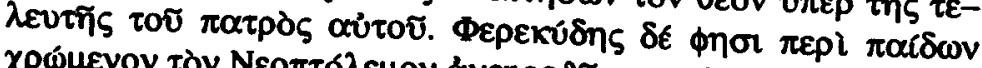

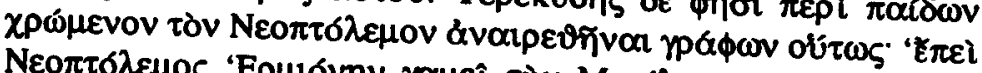

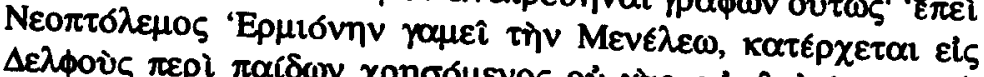

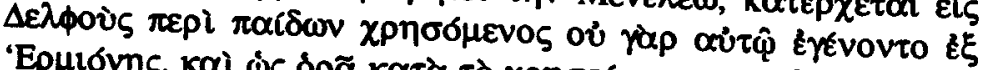

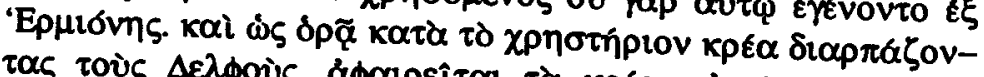

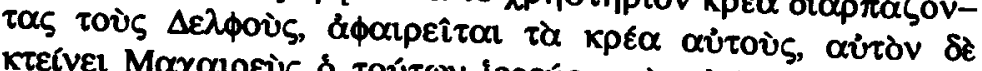

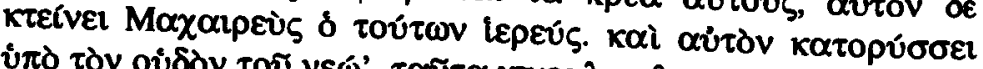

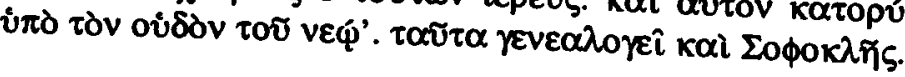

En la primera parte del texto podemos observar la precisión que el escoliasta hace sobre la boda, que no llegó a celebrarse, puesto que no hubo fruto de ese matrimonio. Esto contrasta con el hecho de que Neoptólemo ya hubiera tenido a Moloso/Anfialo con Andrómaca y que, por su parte, posteriormente Hermíone tuviera de Orestes a Tisámeno, lo que demuestra que el enlace entre Hermíone y Neoptólemo no contaba con la aprobación de la 
En la tragedia ática, no fue Eurípides el único que trató el asunto de la rivalidad entre Neoptólemo y Orestes por la mano de la hija de Menelao y Helena. Además del testimonio que acabamos de citar, también por un escolio, en esta ocasión de Eustacio a Odisea, sabemos que Sofocles escribió una tragedia titulada Hermione, cuyo argumento versaba, al menos en parte, sobre la rivalidad de ambos héroes por la posesión de la doncella ${ }^{37}$ (Eust. Od. p. 1479, 10):

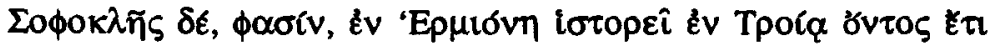

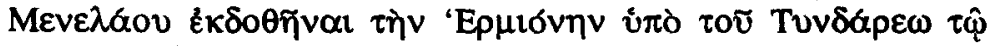

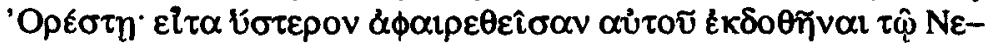

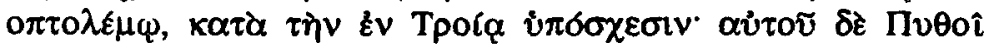

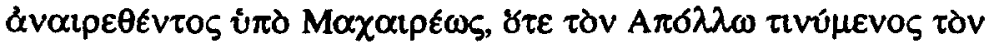

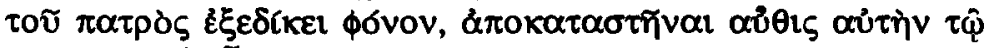

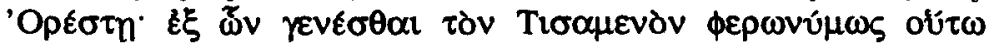

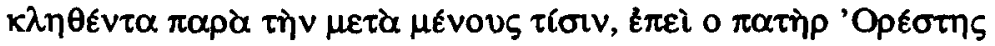

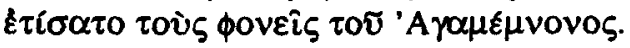

Es probable que, en la escena romana, Pacuvio se basara en esta tragedia de Sófocles para escribir su obra homónima Hermiona ${ }^{38}$, pues el tragediógrafo latino siguió la variante mítica anteriormente citada, como demuestra el testimonio de algunos fragmentos conservados de esta obra (Pac. Herm. fr. 181-2 W).

... Tyndareo fieri contumeliam cuius a te veretur maxime

El siguiente fragmento, atribuido a Orestes, debía de formar parte de un diálogo entre éste y Neoptólemo. En él podemos apreciar la amargura de las palabras de Orestes, que se siente menospreciado al verse privado de la que ya consideraba su esposa (ibid. $184 \mathrm{~W}$ ):

Prius data est quam tibi dari dicta aut quam reditum est Pergamo

Asimismo, el pasaje siguiente refuerza la idea sobre el tratamiento que $\mathrm{Pa}$ cuvio debió de dar a este mito en su tragedia. En él, Hermíone se lamenta de

37 Cf. J. M." Lucas, Sófocles. Fragmentos, pp. 98-9.

38 Livio Andronico también escribio una tragedia con el mismo título, de la cual conservamos un sólo fragmento. Cf. Warmington, Remains of Old Latin. II p. 10. 
las desgracias que va a causar en su familia el enfrentamiento entre ambos pretendientes (ibid. fr. $183 \mathrm{~W}$ ):

quantamque ex discorditate cladem inportem familiae.

Sin duda Ovidio recogio esta variante en Herodias VIII 31-4, donde Hermíone expone con claridad su amor por Orestes frente a la aversión que siente hacia Neoptólemo:

Me tibi Tyndareus, vita gravis auctor et annis, Tradidit; arbitrium neptis habebat avus;

At pater Aeacidae promiserat inscius acti;

Plus quoque, qui prior est ordine, posset avus.

La variante que hace a Tindáreo responsable de haber entregado a su nieta como esposa a Orestes debió de gozar de gran aceptación entre los autores romanos, pues en el sch. Aen. III 330 encontramos de nuevo la misma versión, aunque con una pequeña diferencia: el escoliasta no aclara si Orestes había llegado a contraer matrimonio con Hermíone o sólo había recibido la promesa de que este enlace se habría de producir:

EREPTAE CONIVGIS hanc Hermionen quidam dicunt, cum Oresti esset desponsata, post a Menelao apud Troiam admirante virtutem Pyrrhi, esse illi promissam. alii dicunt a Menelao quidem apud Ilium Pyrrho desponsatam, sed a Tyndareo Oresti, morante apud Troiam Pyrro, ut quidam promissam, ut quidam coniuctam tradunt: quam cum Pyrthus, confisus voluntate Menelai, armatus multitudine rapuisset, ab Oreste insidiis interfectus est.

Por otra parte, los poemas homéricos no hacen referencia alguna a que Menelao hubiese contraído un compromiso entre Hermíone y su sobrino Orestes anterior a la promesa de matrimonio que le hizo a Neoptólemo, cuya única condición era que Troya fuese destruida.

En Odisea IV 1-7 Telémaco llega a Lacedemonia durante los festejos de la boda de Hermíone con Neoptólemo, sin que podamos observar en estos versos ninguna alusión a una disputa motivada por este matrimonio ni tampoco a que hubiera existido algún impedimento para que se celebrase:

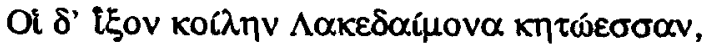

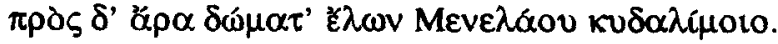




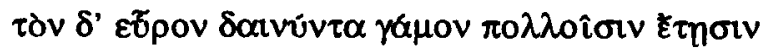

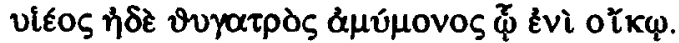

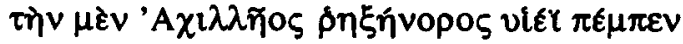

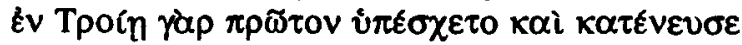

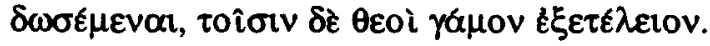

5.3. Por lo que se refiere a la muerte de Neoptólemo, encontramos diversas variantes además de la transmitida por Higino en esta fábula.

La concisión del relato latino nos impide especular acerca de si Orestes en persona fue el ejecutor del hijo de Aquiles o si urdió el complot que acabó con la vida de éste, propagando insidias entre los habitantes de Delfos. La frase Orestes... Neoptolemum Delphis sacrificantem occidit no deja lugar a dudas sobre quién fue el autor directo del crimen.

Esta afirmación difiere del relato que encontramos en la Andrómaca de Eurípides, donde un servidor de Neoptólemo, que lo había acompañado en su viaje a Delfos, expone con todo tipo de detalles el plan tramado por Orestes para acabar con la vida del Eácida (Eur. Andr. 1090-6):

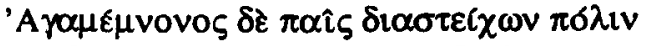

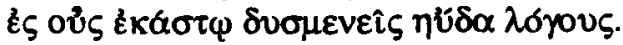

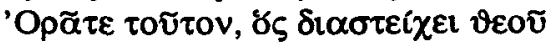

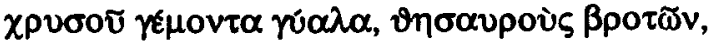

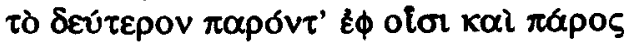

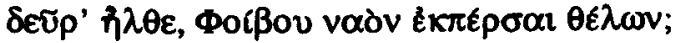

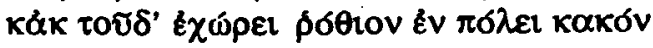

Tras describir cómo se celebró en el santuario la ceremonia de presentación ante el dios, donde Neoptólemo pretendía reparar la ofensa que le había causado a la divinidad anteriormente al pedir justicia por la muerte de Aquiles, el mensajero cuenta la forma en que ocurrí el asesinato de Neoptólemo (ibid. 1111-9):

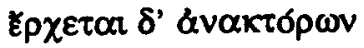

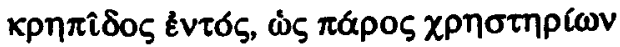

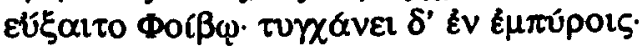

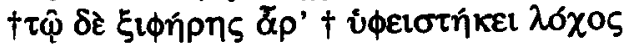

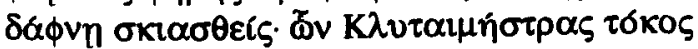

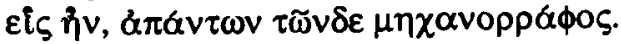

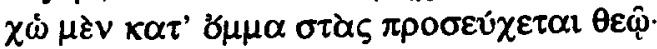

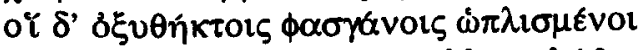

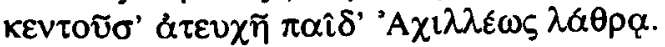


En este pasaje, el hecho de que los asesinos de Neoptólemo se encontraran apostados a la sombra de un laurel, el árbol sagrado de Apolo, ya implica que el crimen contaba con el beneplácito del dios. Esto se confirma en los versos siguientes, en los que el mensajero, después de referirse a la lucha desigual que su amo mantuvo con los delfios, describe el fin del Eácida (ibid. 1149-65):

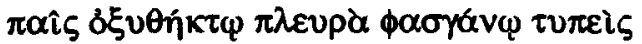

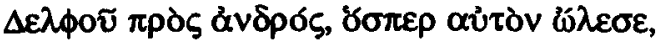

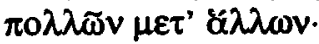

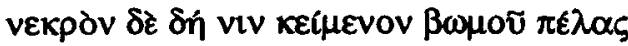

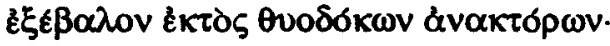

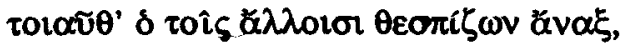

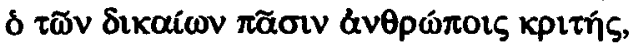
$\delta i x \alpha \varsigma \delta \delta \delta \delta v \tau \alpha \pi \alpha \hat{\imath} \delta$ ' $\varepsilon \delta \rho \alpha \sigma$ ' 'A $\chi \imath \lambda \lambda \varepsilon \omega \zeta$.

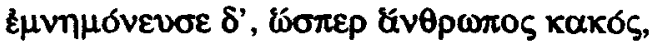

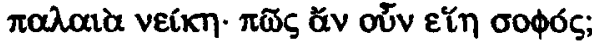

La imposibilidad de transmitir una sola variante se hace patente, en ocasiones, en los mismos repertorios mitograficos.

Respecto a la muerte de Neoptólemo, Apolodoro recoge dos versiones: una coincide con la de Higino en cuanto a la autoría del crimen, atribuyéndolo a Orestes; la otra, sin embargo, es contraria tanto a la de Higino como a la de Eurípides, pues acusa de la muerte del hijo de Aquiles a Maquereo, un sacerdote de Apolo, que así habría vengado la ofensa que Neoptólemo, según este testimonio, había causado al dios (Apd. Ep. VI 14):

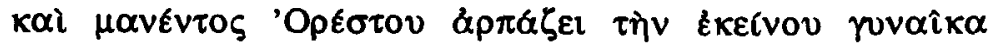

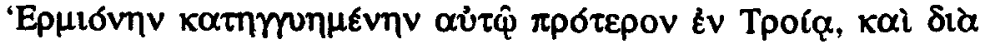

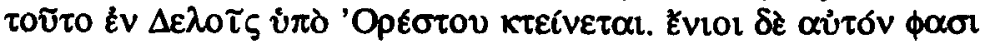

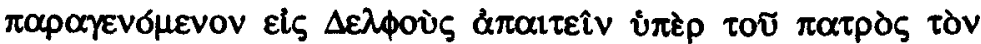

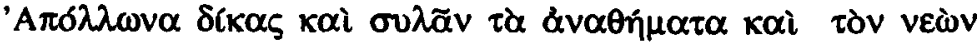

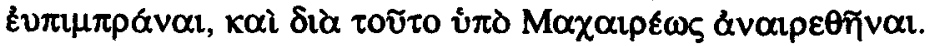

Estrabón recogió esta misma tradición en su Geografía IX 3, 9, donde considera como incidente más verosímil que Neoptólemo atacara el templo de Apolo: 


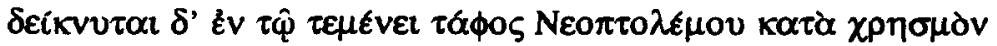

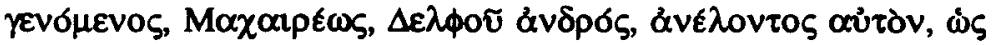

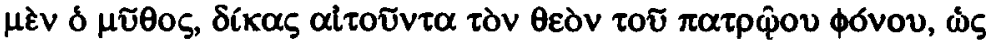

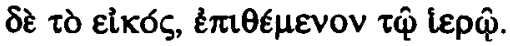

Aún encontramos otra versión diferente en Píndaro, Nemea VII 34-47, donde Orestes no tiene ninguna relación con la muerte de Neoptólemo: éste acudió a Delfos para ofrecer a Apolo las primicias del botín obtenido en Troya y murió en una reyerta surgida con los sacerdotes del templo por causa del reparto de la carne de la víctima del sacrificio; fue enterrado en el recinto del templo. En esta versión, que coincide con el escolio de Eustacio al que nos hemos referido antes ${ }^{39}$, el causante directo de su muerte fue también Maquereo, pero, en realidad, se estaba cumpliendo un oráculo, según el cual un Eácida debía presidir las procesiones en honor de los héroes y los sacrificios que se celebraran en Delfos:

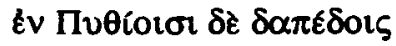

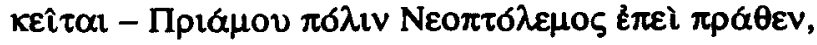

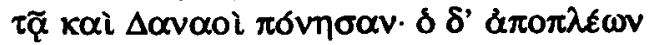

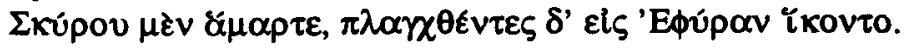

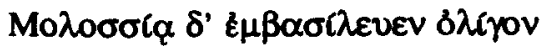

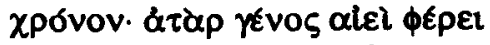

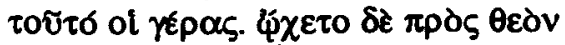

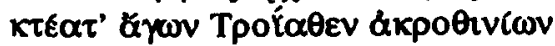

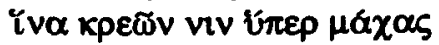

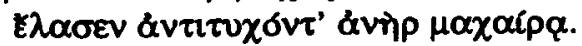

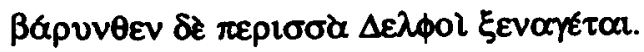

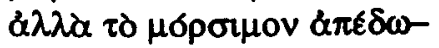

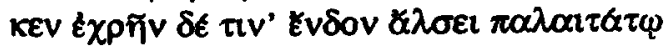

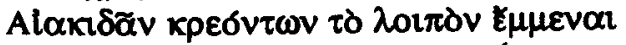

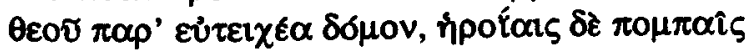

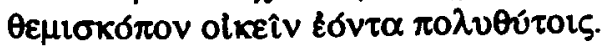

Por último, también Píndaro presenta otra variante en la que aparentemente es el mismo Apolo quien acaba con la vida de Neoptólemo en Delfos co- 
mo venganza por la muerte de Príamo, asesinado por el hijo de Aquiles cuando aquél se encontraba refugiado en el altar de Zeus Herqueios, el protector del hogar ${ }^{40}$ (Pind. Paean VI 104-20).

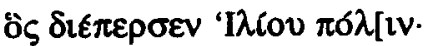

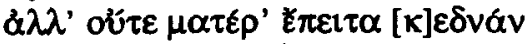

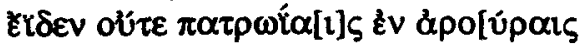

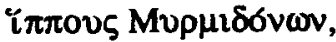

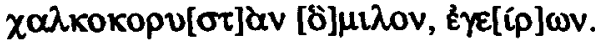

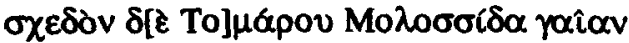

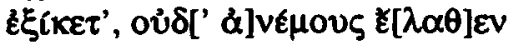

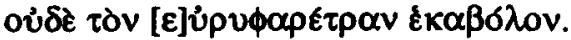

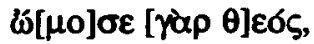

$\gamma \varepsilon[\rho o v] \theta^{\prime} \gamma[\pi] \Pi \rho[\alpha \mu \mathrm{\sigma}$

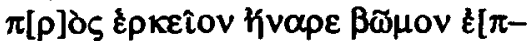

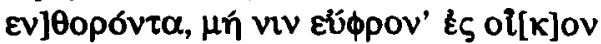

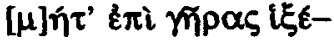

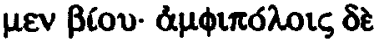

$\kappa] \nu \rho[\imath \widetilde{\alpha} v] \pi \varepsilon \rho \grave{i} \tau \mu \widetilde{\alpha} v$

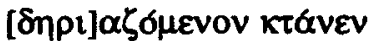

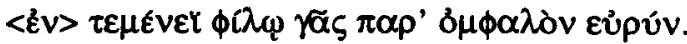

Por tanto, la muerte de Neoptólemo se nos ofrece desde diferentes perspectivas.

El testimonio más antiguo con el que contamos es el de Píndaro, quien, como acabamos de ver, atribuyó la muerte del hijo de Aquiles a Maquereo en la Nemea VII. En el otro testimonio, correspondiente al Peán VI, es Apolo el que acaba con su vida, pero, aunque parece que es el propio dios quien ejecuta al heroe, podría ser que lo hubiera hecho por mediación de uno de los delfios presentes en el combate, quizás Maquereo.

Nos encontramos aquí con una situación paralela a la de la muerte de Aquiles, con parecido grado de confusión respecto a quién lo mató en realidad (Apolo ${ }^{41}$, Paris y Apolo ${ }^{42}$; Paris solo $^{43}$; Paris guiado por Apolo, con una flecha ${ }^{44}$; Paris ayudado por Deífobo, con la espada, en el templo de Apolo Tim-

40 Cf. Eur. Tr. 17.

41 Il. XXI 277. Aesch. fr. $350 \mathrm{~N}^{2}$. Soph. Ph. 334-5. Eur. Andr. 1106-8.

42 Il. XXII 358-60.

${ }^{43}$ Eur. Hec. 387; Andr. 655.

44 Verg. Aen. VI 56-58. 
breo $^{45}$ ). Este paralelismo aumenta si tenemos en cuenta que el dios que llevó a cabo ambas muertes fue Apolo y que las víctimas eran padre e hijo.

Por su parte, Eurípides otorga la autoría del crimen a los delfios, instigados por Orestes. Apolodoro transmite las dos versiones, o bien Orestes o bien Maquereo, coincidiendo con el escolio a Eurípides, Orestes 1655. Estrabón afirma que el asesino fue Maquereo, mientras que Higino conviene significativamente con el compilador del repertorio mitografico de Apolodoro, asignando la ejecución del crimen a Orestes.

Esta falta de acuerdo en un hecho tan importante como es la muerte de un héroe demuestra que, cuando se quiere abordar el estudio de un personaje mítico, hay que especificar época, autor y género literario en el que se transmite una versión determinada.

5.4. No quiero terminar el análisis de esta fábula sin una breve referencia al lugar en que fue sepultado Neoptólemo.

Todas las versiones que conocemos sitúan la tumba en el recinto del templo de Apolo en Delfos. Sólo se diferencian en la apreciación que hacen del motivo por el cual yace allí. Píndaro y Estrabón afirman que se daba cumplimiento a un oráculo. En cambio, Eurípides pone en boca de Tetis, en el epilogo de Andrómaca 1239-42, las siguientes palabras:

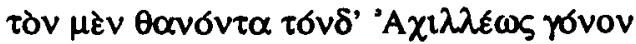

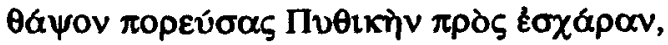

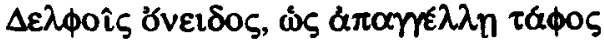

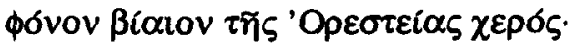

Frente a toda la tradición anterior, Higino aporta una variante nueva: no hay ninguna sepultura y los restos de Neoptólemo fueron esparcidos por las fronteras de Ambracia, en el Epiro.

6. Para finalizar, podemos extraer algunas conclusiones de lo expuesto aquí:

6.1. Es evidente que los mitos tienen un tratamiento muy diferente, lo que reafirma en qué medida la mitología clásica va ligada a la literatura.

6.2. Los repertorios mitográficos, entre ellos, naturalmente, el de Higino, tienen una gran importancia no sólo como meros catálogos donde se recogen, abreviadas, leyendas de héroes y dioses; también aportan criterios subjetivos, como la posible justificación del crimen de Orestes, y variantes míticas inéditas ${ }^{46}$.

45. Cf. Dictys IV 10-11.

46 A lo ya expuesto, podemos añadir, p. ej. que Higino, Fab. CVIII, fue el primero - si consideramos que la obra fue escrita hacia el s. I- en referirse al talón como la única parte mortal del cuerpo de Aquiles. 
6.3. Hay que distinguir dos tipos de variantes en un mito:

6.3.1. En primer lugar, las que afectan a datos puntuales, pero no a la caracterización del personaje. Tienen un gran interés filológico, pero no influyen en la transmisión literaria de un personaje mítico. Éste es el caso, por ejemplo, de Poliméstor. El rey tracio es el paradigma de la traición y de la ambición. Las pequeñas variantes que encontramos en Higino relativas a quien lo cegó o a su eventual matrimonio con Electra no son significativas. Lo mismo se puede decir de las múltiples versiones referentes a la muerte de Neoptólemo.

6.3.2. En segundo lugar, hay que considerar las variantes que conforman una caracterización del personaje distinta a la de la tradición anterior. Un ejemplo de este tipo es el que encontramos en el escolio a Orestes 1655 de Eurípides, donde Neoptólemo, un guerrero cruel, capaz de despeñar a Astianacte y de sacrificar a Políxena, aparece revestido de unos rasgos de humanidad, inusuales por completo, cuando acude a Delfos para consultar a Apolo el motivo por el que no tenía descendencia con Hermíone.

6.3.3. También podemos situar entre estas variantes caracterizadoras del mito la relativa al no enterramiento de Neoptólemo en Delfos sino en Ambracia, como transmite Higino. Es importante, puesto que contradice la tradición anterior relativa al oráculo según el cual un Eácida debía presidir las procesiones en honor de los héroes y los sacrificios que se celebraran en Delfos.

6.3.4. Asimismo, en lo referente a la leyenda de Polidoro y Deípilo, resulta de gran interés el testimonio de Higino que alude a la posibilidad de intercambiar a los niños que Iliona criaba conjuntamente. 